\title{
John S. Bell
}

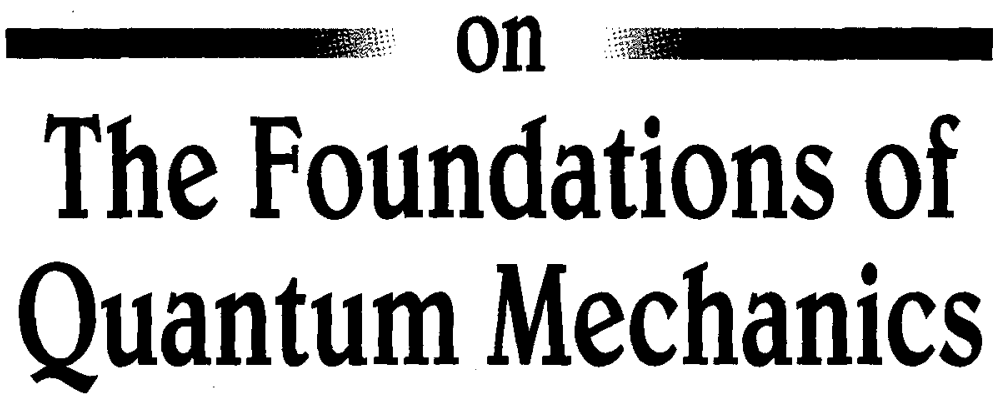


This page is intentionally left blank 


\section{John S. Bell}

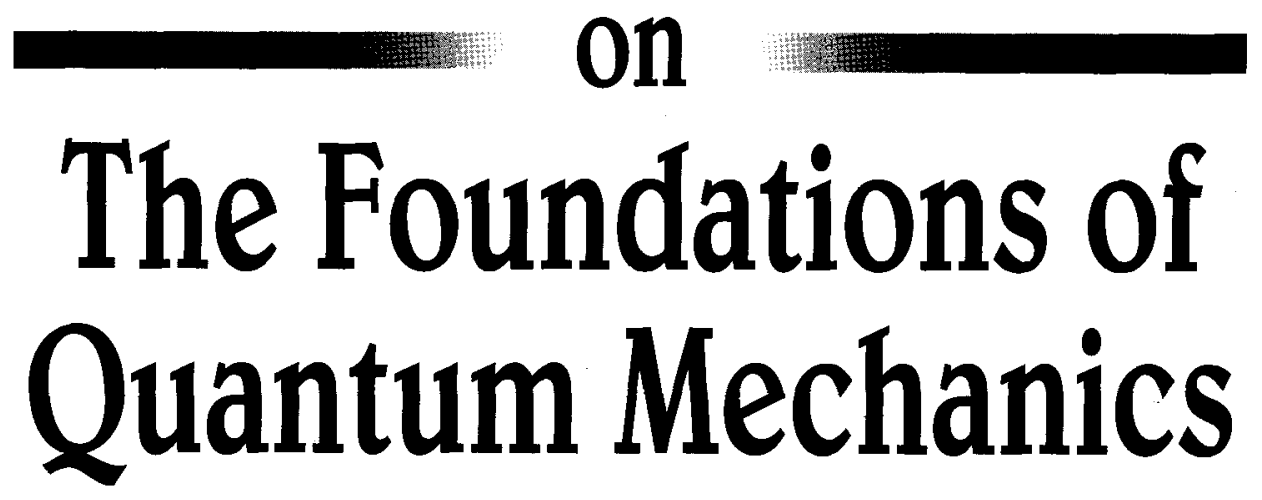

Editors

M. Bell

CERN

K. Gottfried

Cornell University

\section{Veltman}

University of Michigan, Ann Arbor 


\section{Published by}

World Scientific Publishing Co. Pte. Ltd.

P O Box 128, Farrer Road, Singapore 912805

USA office: Suite 1B, 1060 Main Street, River Edge, NJ 07661

UK office: 57 Shelton Street, Covent Garden, London WC2H 9HE

\section{British Library Cataloguing-in-Publication Data}

A catalogue record for this book is available from the British Library.

\section{JOHN S. BELL ON THE FOUNDATIONS OF QUANTUM MECHANICS}

Copyright $\odot 2001$ by World Scientific Publishing Co. Pte. Ltd.

All rights reserved. This book, or parts thereof, may not be reproduced in any form or by any means, electronic or mechanical, including photocopying, recording or any information storage and retrieval system now known or to be invented, without written permission from the Publisher.

For photocopying of material in this volume, please pay a copying fee through the Copyright Clearance Center, Inc., 222 Rosewood Drive, Danvers, MA 01923, USA. In this case permission to photocopy is not required from the publisher.

ISBN $981-02-4687-0$

ISBN 981-02-4688-9 (pbk) 


\section{Publisher's Note}

The material in this volume first appeared as Section 3 of Quantum Mechanics, High Energy Physics and Accelerators (World Scientific, 1995). It has been reprinted owing to demand from the physics community. Once again, World Scientific would like to thank the publishers of the various books and journals for their permission to reproduce the articles found in Quantum Mechanics, High Energy Physics and Accelerators. 


\section{Contents}

1. On the Problem of Hidden Variables in Quantum Mechanics

Rev. Mod. Phys. 38 (1966) 447-452

2. On the Einstein Podolsky Rosen Paradox Physics 1 (1964) 195-200

3. The Moral Aspect of Quantum Mechanics with $M$. Nauenberg Preludes in Theoretical Physics - In Honor of V. F. Weisskopf, eds. A. De-Shalit, H. Feshbach and L. Van Hove (North-Holland, Amsterdam, 1966), pp. 279-286

4. Introduction to the Hidden-Variable Question Foundations of Quantum Mechanics - Proc. Int. Sch. of Physics 'Enrico Fermi,' course IL, ed. B. d'Espagnat (Academic, New York, 1971), pp. 171-181

5. The Measurement Theory of Everett and de Broglie's Pilot Wave Quantum Mechanics, Determinism, Causality, and Particles, eds. M. Flato et al. (Reidel, Dordrecht, 1976), pp. 11-17

6. Subject and Object

The Physicist's Conception of Nature, ed. J. Mehra

(Reidel, Dordrecht, 1973), pp. 687-690

7. On Wave Packet Reduction in the Coleman-Hepp Model Helv. Phys. Acta 48 (1975) 93-98

8. The Theory of Local Beables

Epistemological Lett. 9 (1976); Dialectica 39 (1985) 86-96 50

9. How to Teach Special Relativity Prog. Sci. Culture 1 (1976)

10. Einstein-Podolsky-Rosen Experiments

Proc. Symp. on Frontier Problems in High Energy Physics

(in Honour of Gilberto Bernardini on His 70th Birthday),

Pisa, June 1976, pp. 33-45

11. Free Variables and Local Causality

Epistemological Lett. 15 (1977); Dialectica 39 (1985) 103-106 
12. Atomic-Cascade Photons and Quantum-Mechanical Nonlocality Invited talk at Conf. European Group for Atomic Spectroscopy, Orsay-Paris, 10-13 Jul. 1979; Comments Atom. Mol. Phys. 9 (1980) 121-126

13. de Broglie-Bohm, Delayed-Choice, Double-Slit Experiment, and Density Matrix

Int. J. Quantum Chem.: Quantum Chem. Symp. 14 (1980) 155-159

14. Quantum Mechanics for Cosmologists

Quantum Gravity 2, eds. C. Isham, R. Penrose and D. Sciama

(Oxford University Press, 1981), pp. 611-637

15. Bertlmann's Socks and the Nature of Reality

Journal de Physique, Colloque C2, Suppl. 3 (1981) 41-62

16. On the Impossible Pilot Wave

Found. Phys. 12 (1982) 989-999 148

17. Beables for Quantum Field Theory

CERN-TH.4035/84 (1984); Quantum Implications, ed. B. Hiley

(Routledge and Kegan Paul, 1987), p. 227

18. EPR Correlations and EPW Distributions

New Techniques and Ideas in Quantum Measurement Theory (21-24 Jan. 1986),

ed. D. M. Greenberger; Ann. N.Y. Acad. Sci. 480 (1986) 263

19. Are There Quantum Jumps?

Schrödinger: Centenary of a Polymath (Cambridge University Press, 1987)

20. Six Possible Worlds of Quantum Mechanics

Proc. Nobel Symp. 65: Possible Worlds in Humanities, Arts and Sciences

(Stockholm, 11-15 Aug. 1986), ed. S. Allén (Walter de Gruyter, 1989), pp. 359-373

21. Against 'Measurement'

Phys. World 3 (1990) 33-40 208

22. La Nouvelle Cuisine

Between Science and Technology, eds. A. Sarlemijn and

P. Kroes (Elsevier/North-Holland, 1990), pp. 97-115.

23. In Memory of George Francis FitzGerald

Lecture given at Trinity College, Dublin, on the 100th anniversary of the

FitzGerald contraction. Published in Phys. World - 5 (1992) 31-35.

Abridged version written by Denis Weaire, Trinity College, Dublin 